\title{
Risks on Optimization of Life Cycle of Technology of Installation of Transformed Low- rise Buildings from Sandwich Panels
}

\author{
Alexander Pleshivtsev ${ }^{1 *}$, Oleg Korol ${ }^{1}$ and Reza Barkhi $^{2}$ \\ ${ }^{1}$ Moscow State University of Civil Engineering, Yaroslavskoe shosse, 26, Moscow, 129337, Russia \\ ${ }^{2}$ Virgina Tech University, Pamplin 3090, 880 Campus Drive, Blacksburg, VA 24061, USA
}

\begin{abstract}
One of the main issues of development of organizational and technological solutions for the rapid construction of transformable lowrise buildings of sandwich panels (transformable low-rise buildings) is to improve the methods of industrial production through the use of highperformance mechanization. Increase of working capital efficiency, which makes prefabricated transformable buildings of sandwich panels the most attractive technical solutions for the investor-customer and allow you to quickly recoup the investment. Traditional measures of improvement of the organization of processes and specific directions of development of the organization of construction production of (transformable low-rise buildings) in modern conditions are given. We highlight the technological component of sustainability, and the specifics of security in the modern conditions of technological development and increasing innovativeness.
\end{abstract}

\section{Introduction}

For such a large country as Russia, with an economy with prospects for development, construction risk issues play a particularly important role. New construction can be viewed as a new product for various purposes, in particular the development of organizational and technological solutions for the rapid construction of transformable low-rise buildings from sandwich panels (transformable low-rise buildings) [1,2]. Raising capital for the implementation of construction projects requires the validity of all financial indicators and the involvement many individuals in the implementation of the investment construction project. Construction is closely related to investment activities given that construction projects require significant start-up capital, and generate future cash flows. Both the investor and the construction company are interested in ensuring that the project brings maximum profit and is expedient for implementation on a number of financial indicators. However, there may be a number of issues on which the interests of participants in the investment process will differ [3-5], potentially resulting in agency conflicts manifesting into construction risks.

Today, in Russia, the risks of investing in the construction of (transformable low-rise buildings) production are characterized by increased complexity of diagnosis, and the risks are much higher than investments in many other sectors of the economy. This puts the

\footnotetext{
*Corresponding author: perspektiva-aa@mail.ru
} 
problem of optimizing the risks of the product life cycle at the forefront in the implementation of many investment projects [1-10].

Despite the importance of the problem of risk optimization, there is no generally accepted definition of the essence of the risk of interaction of participants of the investment process in construction [11-13].

Initially, it is necessary to find out who and at what stage of the life cycle of the construction production project (transformable low-rise buildings) does the risk need to be properly optimization.

In modern Russian construction, some projects are complex and intricate. The introduction of new complex mechanisms of financing the construction projects, there do not see to be a corresponding reduction in the investment and financial risks. Financial and credit mechanisms link the final consumer of housing with the supplier of funds for construction with builders. At the same time, all three parties have their own interests in risk optimization and the authority to deal with this issue $[14,16]$.

Planning determines the order, sequence and timing of risk optimization activities. The risks involved are those that can be identified and assessed prior to the start of the project. Such risks constitute a risk optimization plan, which contains a list of identified project risks, their assessment and processing strategy. In addition, the risk focuses on responsible persons and other control processes that will help optimize the risks $[15,17]$.

Focusing on the methods of risk identification, we can identify many approaches to the classification of risks. According to the common approach of Construction Risk Management System (CRMS) in foreign countries, proposed by American researchers and analysts, the process of risk identification consists of six stages:

1)identification of uncertainties;

2)preparation of a preliminary checklist;

3)consequence scenarios;

4)a reflection of risks;

5)systematic list of risks;

6)total risk.

Optimization of risks includes steps for the selection and implementation of various measures to reduce to the acceptable levels of risks on each dimension of risk. We focus mechanisms to manage risks: 1) acceptance, 2) transfer, 3) mitigation, 4) evasion [18]. The choice of the risk optimization method is based on the qualitative and quantitative assessment of the project risks.

\section{Methodology}

The methodology of the research is a systematic approach that focuses on the methods of analysis and comparative efficiency of decisions made by the enterprise. We combine methods from mathemats and statistics to develop measurable indicators based on statistical modeling and qualitative expert assessments.

The research methods allow us to rank enterprises based on their capacity for innovative development. The effective optimization of risks and the proper implementation of enterprises help with the critical need to address: 1) increasing demand for transformable low-rise building products, and 2) increasing competitiveness [19-21].

\subsection{Development of a new generation of pre-fabricated transformable low-rise buildings}

Development of a new generation of pre-fabricated transformable low-rise buildings from sandwich panels should take into account the full life cycle of the system, consisting of: economic calculations, design documentation, organizational and technological solutions, development of capacity, return on investment, and economic impact [22, 25]. 
Table 1 illusrtates the life cycle described above (from origin to decline) in a graph. Each life cycle phase can be described mathematically depending on the nature of external and internal processes that occur at a particular time interval [23-26].

Table 1. Mathematical functions describing the dynamics of life cycle phases.

\begin{tabular}{|l|l|c|c|}
\hline $\begin{array}{l}\text { Stage of the } \\
\text { life cycle }\end{array}$ & Of a function Symbol & $\begin{array}{c}\text { The function } \\
\text { Equation }\end{array}$ & $\begin{array}{l}\text { Of the curve that } \\
\text { describes the function }\end{array}$ \\
\hline Origin & $\begin{array}{l}\text { Combined } \\
\text { exponential-power } \\
\text { function }\end{array}$ & $\mathrm{Y}^{\mathrm{at}} \times \mathrm{e}^{\mathrm{at}} \times \mathrm{t}^{\mathrm{B}}$ \\
$\begin{array}{l}\text { The } \\
\text { acceleration } \\
\text { of growth }\end{array}$ & $\begin{array}{l}\text { Of the Exponential } \\
\text { function }\end{array}$ & $\mathrm{Y}=\mathrm{a} \times \mathrm{Se}^{\mathrm{t}}$ \\
\hline $\begin{array}{l}\text { The } \\
\text { slowdown }\end{array}$ & $\begin{array}{l}\text { In the Second } \\
\text { function Tornquis }\end{array}$ & $\mathrm{Y}=\mathrm{k}(\mathrm{t}+\mathrm{a}) /(\mathrm{t}+\mathrm{B})$ \\
\hline The Maturity & Of The Parabola & $\mathrm{Y}=\mathrm{a}+\mathrm{Bt}-\mathrm{ct}^{2}$ & \\
\hline The Decline & Video & $\mathrm{Y}=\mathrm{a}-\mathrm{Bt}$
\end{tabular}

The life cycle model of the developed systems of a new generation of (transformable low-rise buildings) is presented in the (see table 2).

Table 2. A generalized version of the process life cycle construction of modern transformable lowrise buildings made of sandwich panels

\begin{tabular}{|l|l|}
\hline 1 & Scientific research \\
\hline 2 & Concept development \\
\hline 3 & Technical study \\
\hline 4 & Economic feasibility studies \\
\hline 5 & The rationale for the techno-economic estimation \\
\hline 6 & Develop a requirements specification \\
\hline 7 & The design of the prototype \\
\hline 8 & Prototype manufacturing \\
\hline 9 & Prototype test \\
\hline 10 & Project adjustment \\
\hline 11 & Production of a series of samples \\
\hline 12 & Test lots of samples \\
\hline 13 & Project adjustment \\
\hline 14 & Serial production \\
\hline
\end{tabular}

Concrete measures to create transformable low-rise buildings of a new generation can be solved through folding and sliding structures with unified nodes, with lighter-weight bearing and enclosing structures [27-30]. 
To optimize the process of installation technology of the transformed low-rise building from sandwich panels, we first develop the option of improving the manufacturability of all construction operations. This option is proposed as a system of high-tech solutions, and is considered not only at the stage of construction, but also in the process of operation, repair, and dismantling, at all stages of the life cycle (LC):

$$
\mathrm{M}=\mathrm{f}\left(\mathrm{S}_{\text {life-cycle }}\right)+\left\{\mathrm{S}_{\mathrm{ctr}}\right\}>\max
$$

M - is a model of increasing the technological effectiveness of the construction process,

$\mathrm{S}_{\text {life-cycle }}$ - stages of the life cycle of the house (transformable low-rise buildings),

$\mathrm{S}_{\mathrm{CTR}}$ - stages of development and implementation of advanced design and technological solutions.

Such basic technological parameters of fast construction of the transformed low-rise building from sandwich panels as, labor costs and machine-time, cost and duration of works can be considered and estimated as the sum of costs, at the stages of preparation and maintenance, design $\left(\mathrm{C}_{\mathrm{pr}}\right)$ and construction $\left(\mathrm{C}_{\mathrm{con}}\right)$, and at the stages of the life cycle of the maintenance $\left(\mathrm{C}_{\text {maint }}\right)$, repair $\left(\mathrm{C}_{\mathrm{rep}}\right)$, reconstruction $\left(\mathrm{C}_{\mathrm{rek}}\right)$, by means of the following modeling [23]:

$\mathrm{M}\left(\mathrm{C}_{\mathrm{lcc}}\right)=\mathrm{C}_{\text {prep.design. constr. }}+\mathrm{C}_{\text {cost during. oper. rep. reconst }}+\mathrm{CTR}_{\text {des.const. tran. }} \rightarrow \min ,(2)$

where,

$\mathrm{C}_{\text {lcc }}$ - life cycle costs,

$\mathrm{C}_{\text {prep.design. constr. }}$ - costs at the stages of preparation, design and construction,

$\mathrm{C}_{\text {cost during. oper. rep. reconst }}$ - costs during operation, repair and reconstruction,

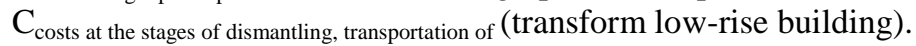

Taking into account the above on schemes 1 , and 2, the scheme of development of the approximate variant of technology of installation of the transformed low-rise building from sandwich panels is shown in Figures 1 and 2).

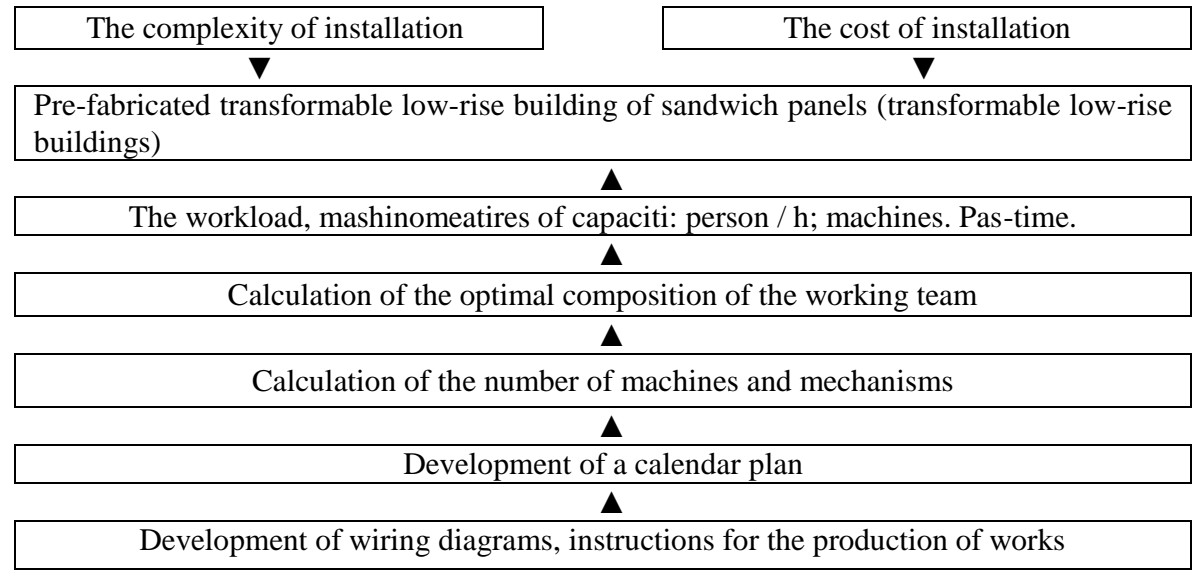

Fig. 1. Development of an approximate installation technology transformable low-rise building of sandwich panels. 


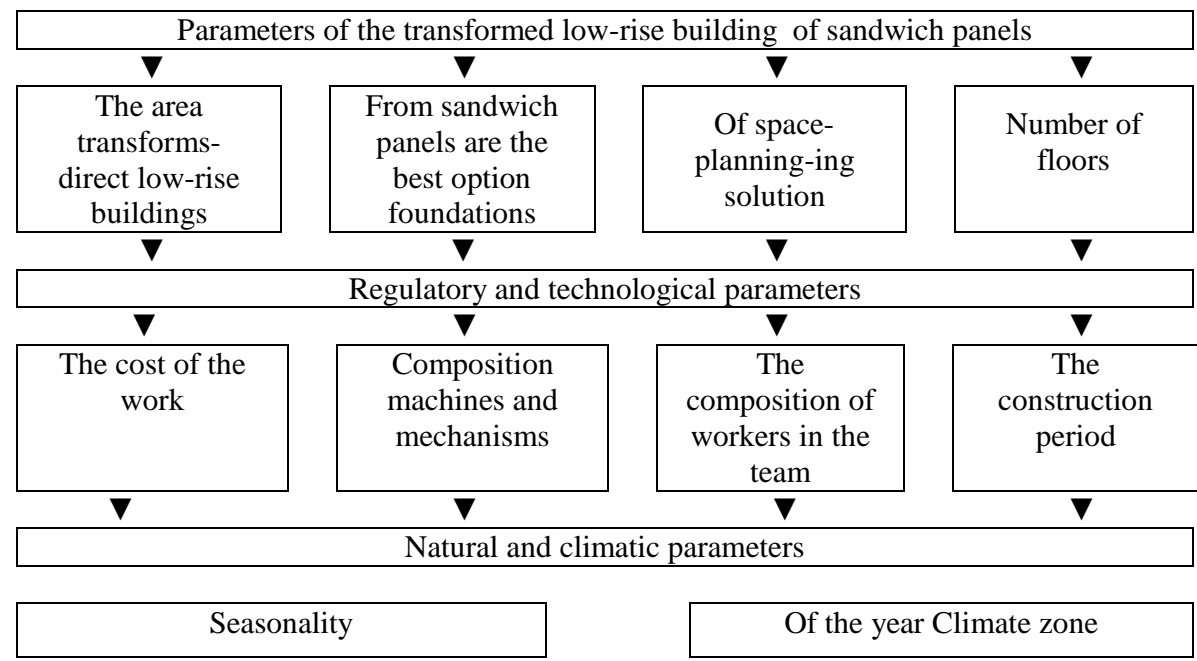

Fig. 2. An exemplary embodiment of parameters of technological schemes for installation of the transformed low-rise building of sandwich panels.

\section{Results and Discussion}

In the present work, the peopoaws algorithm of formation of the optimal model of technology of rapid construction of low-rise buildings transformed from sandwich panels, improved design and technological solutions for installation of (transform low-rise building) sandwich panels, although not without risks [15-19].

As in the case of design, there are problems in the construction of transformation of low-rise building; for example, the rise in price in the presence of a complex site and the need to install panels with a crane in a small area in the presence of electric wires above the ground presents significant risk.

Transportation of some panels requires special transport, which affects among other things, the budget and requirements for access roads.

\section{Conclusions}

Compliance with technology to guarantee and facilitate expansion and future scaling of operations, and the complex technology the add to greater risk of any deviations from the standared practice [28-30].It is critical to identify key factors and patterns that affect the risk on the optimization of the technological mode transformable prefabricated low-rise buildings of industrial sandwich panels. These include reducing the complexity and cost of installation from increasing the size, degree of prefabrication and weight of the panels, reducing the complexity of the device joints, reducing the duration of building the number and skills of workers in the unit, and shifting and level of mechanization.

Pre-fabricated technologies are in demand in the developed stable market in the construction of large volumes of standard housing. Taking into account the cultural norms and Russian mentality, today the use of pre-fabircated technologies is more likely possible only in the case of construction of social housing and similar programs with state-dictated conditions. Buyers of business class houses are likely to choose classical construction technologies and are ready to experiment only at the level of finishing, but less likely to compromise on basic building materials. 
This work was financially supported by Ministry of Science and Higher Education of the Russian Federation (\#NSh-3492.2018.8).

\section{References}

1. Korol E. A. the Solution of problems of organizational-technological simulation of building processes / Korol ' E. A., Komissarov S. V., Kagan P. B., S. G. Arutyunov. Industrial and civil engineering, 2011.- № 3. - S. 43-45.

2. Korol E. A. Pleshivtsev A.A. The technology of construction of low-rise buildings from sandwich panels: dis. kt: 05.23.08 / Moscow, 2017. - p. 56-67.

3. Nanazashvili I. Kh., Pleshivtsev A. A. the Development of new territories, the construction of comfortable and affordable housing.// Construction materials, equipment and technologies of XXI century, 2 (145), 2011.

4. Nikol'skiy, M. S. the Technology of construction of individual residential houses of the industrial sandwich panels // Bulletin of civil engineers / co-author Kazakov Yu. N. SPb.: Ed. Spbgasu. - 2011. - № 2. - P. 99-104.

5. Nikolsky M. S. modeling of rational technological solutions to reduce the complexity and cost on the basis of multi-criteria optimization. Mater, teach.- prakt. Conf., poev, PA-mint, doctor of technical Sciences, prof. V. M. Vasilyeva "construction Management in modern conditions", St. Petersburg, VITU, 2009. - P. 200-207.

6. Pleshivtsev, A. A., Principles and laws of system organization rapid construction of transformable residential buildings (model of organization for fast construction of transformable residential buildings)./ City building.- 2013. N 6.

7. Pleshivtsev A.A. The Basic concept of a systematic approach in the evaluation of the production and construction of transformed prefabricated low-rise residential buildings. Report at the International scientific conference "Topical issues of technical Sciences" Russia, Moscow, March 27-29, 2014.

8. Pleshivtsev A.A. Systematic approach in the construction of BZ residentia buildings./ City building.- 2014. No. 3.

9. Prikin B. V. Techno-economic analysis of production. - Moscow: UNITY-DANA, 2003. - $476 \mathrm{p}$.

10. Semenov V. S. low-rise pre-Fabricated buildings from light steel thin-walled constructions / V. S. Semenov, A. M. Rehovoth, A. Kondrashov. - Bulletin of the Kyrgyz-Russian Slavic University, 2008. - Vol. 8, № 9. - S. 154-158.

11. Strikin B.S., Pleshivtsev A.A., The Current state of the design and selection of factors for the development of the objects of the cottage development in the main phases of the life cycle. Sat. nauch. Tr., Voronezh, VGASU, 2009 (0,6 p.1.).

12. Suetina T. A., Nanazashvili I. Kh., Pleshivtsev, A. A., Organization of construction eco-friendly prefabricated buildings. Vestnik VolgGASU. Ser.: Page and archit. 2013. Vol.31 (50).

13. Sichov S.A. The Method of selection of complex mechanization schemes of modular construction. - Engineering Bulletin of don, 2015. - Vol.38. №4 (38). - p. 65.

14. Tikhonov N. With. Prefabricated buildings of lightweight construction materials and their engineering / N. With. Tikhonova, G. A. Svishchev, I. O. Sedliarou. - Design and technology, 2014. - № 39 (81).- S. 61-66.

15. Chulkov V. O. Infography. Vol.1. Infographic multilevel modeling: a Modular course of lectures./ - M.: SOR-ARTUS, 2007.

16. Chulkov V. O., Kazaryan p. p. System approach to certification of manual labor mechanization and transportation of building materials and structures // "Industrial and civil construction", Zh. №2, 2009. 
17. Borkovskaya V. G., Belikova E. S. Risks and the actual state of the quality management system at the enterprises of the construction industry. International scientific and technical journal "real Estate: Economics, management".Economics and management of real estate. Moscow. 4 - 2017. 39-43c

18. Borkovskaya V. G. Project risks. Scientific review № 23, 2015. Moscow. 212-214 p.

19. Agzamov R. A., Burkov V. G., Borkovskaya V. G., Nasonova T. V. management of program risks on the basis of qualitative assessments of their characteristics. Economics and management of management systems, No. 4 (26), 2017. $42-49$ p.

20. Borkovskaya V.G. Environmental and economic model life cycle of buildings based on the concept of "Green Building". Журнал Applied Mechanics and Materials (467). Materials Science and Mechanical Engineering. Chapter 2: Building Materials and Construction Technologies. Pages 287-290. December 2013. DOI: 10.4028/www. in the construction business and education. Applied

21. Mechanics and Materials. (Volumes 475-476). Chapter 15: Engineering Management. December 2013. Pages 1703-1706. DOI: 10.4028/www.scientific.net/AMM.47476.1703scientific. net/AMM.467.287

22. Victoria G. Borkovskaya, Evgeniy Degaev, Irina Burkova. Environmental economic model of risk management and costs in the framework of the quality management system. MATEC Web of Conference 2018, International Scientific Conference Environmental Science for Construction Industry - ESCI 2018. Volume 193 (2018).

23. Victoria G. Borkovskaya, David Passmore. Application of Failure Mode and Effects Analysis in Ecology in Russia. MATEC Web of Conference 2018, International Scientific Conference Environmental Science for Construction Industry - ESCI 2018. Volume 193 (2018).

24. Victoria G. Borkovskaya, David Passmore. Behavioral engineering model to identify risks of losses in the construction industry. Advances in Economics, Business and Management Research (France-Netherlands). Atlantis Press. In press.

25. Korolchenko D.A., Degaev E.N., Sharovarnikov A.F. Dependence of Fire Extinguishing Efficacy of Low Expansion Foams Solutions Homology Sodium Sulfate on the Molecular Weight of the Surfaceactive Substances. 2nd International conference on material engineering and application: (ICMEA-2015). DOI 10.12783/dtmse/icmea2015/7238.

26. Degaev E, Suvorova A and Suhova A. Influence of total head of foam on optimum intensity and minimum particular expense solution size of foamer // IOP Conf. Ser.: Mater. Sci. Eng. 365 (2018) 032019. DOI: https://doi.org/10.1088/1757899X/365/3/032019.

27. Degaev E, Razvalyaeva V and Sabenina S. Formation of water film from aqueous film forming foam drops on the surface of oil products // IOP Conf. Ser.: Mater. Sci. Eng. 365 (2018) 062037. DOI: https://doi.org/10.1088/1757-899X/365/6/062037.

28. Korolchenko D.A, Degaev E.N. and Sharovarnikov A.F. Determination of the Effectiveness of Extinguishing Foaming Agents in the Laboratory. 2nd International conference on material engineering and application: (ICMEA-2015), pp 17-22. DOI: 10.12783/dtmse/icmea2015/7237.

29. Degaev E.N. New classification of foaming agents for fire extinguishing // MATEC Web of Conferences 193, 02032 (2018). DOI: https://doi.org/10.1051/matecconf/201819302032.

30. Degaev E.N. and Korolchenko D.A. Improving Fire Protection of Pontoon Tanks or Floating Roof Tanks // MATEC Web of Conferences 117, 00036 (2017). DOI: https://doi.org/10.1051/matecconf/201711700036. 